\title{
Control of Distributed Uninterruptible Power Supply Systems
}

\author{
Josep M. Guerrero, Senior Member, IEEE, Lijun Hang, and Javier Uceda, Fellow, IEEE
}

\begin{abstract}
In the last years, the use of distributed uninterruptible power supply (UPS) systems has been growing into the market, becoming an alternative to large conventional UPS systems. In addition, with the increasing interest in renewable energy integration and distributed generation, distributed UPS systems can be a suitable solution for storage energy in microgrids. This paper depicts the most important control schemes for the parallel operation of UPS systems. Active load-sharing techniques and droop control approaches are described. The recent improvements and variants of these control techniques are presented.
\end{abstract}

Index Terms-Droop method, load sharing, microgrids, parallel connection, uninterruptible power supply (UPS).

\section{INTRODUCTION}

D ISTRIBUTED generation (DG) is an emerging concept to decentralize the management of electricity production. However, DG makes no sense without distributed storage energy systems. Thus, the parallel operation is a special feature of high-performance uninterruptible power supply (UPS) systems [1]-[21]. The parallel connection of UPS inverters is a challenging problem that is more complex than paralleling dc sources, since every inverter must properly share the load while staying synchronized. In theory, if the output voltage of every inverter has the same amplitude, frequency, and phase, the current load could equally be distributed. However, due to the physical differences between the inverters and the line impedance mismatches, the load will not properly be shared. This fact will lead to a circulating current among the inverters that can damage or overload them.

The fast development of digital signal processors has brought about an increase in control techniques for the parallel operation of UPS inverters. These control schemes can be classified into two main groups with regard to the use of control wire interconnections [7]. The first one is based on active loadsharing techniques, and the major part of them is derived from control schemes of parallel-connected dc-dc converters, such as centralized [22], [23], master-slave (MS) [24]-[32], average load sharing (ALS) [33]-[41], and circular chain control (3C) [42], [43]. Although these control schemes achieve both good output-voltage regulation and equal current sharing, they need

Manuscript received February 16, 2008; revised April 7, 2008. Published July 30, 2008 (projected).

J. M. Guerrero is with the Department of Automatic Control and Computer Engineering, Technical University of Catalonia, 08036 Barcelona, Spain (e-mail: josep.m.guerrero@upc.edu).

L. Hang is with the College of Electrical Engineering, Zhejiang University, Hangzhou 310027, China.

J. Uceda is with the División de Ingeniería Electrónica, Universidad Politécnica de Madrid, 28006 Madrid, Spain.

Digital Object Identifier 10.1109/TIE.2008.924173 critical intercommunication lines among modules that could reduce the system reliability and expandability.

The second kind of control scheme for the parallel operation of inverters is mainly based on the droop method [44]-[74]. This technique consists of adjusting the outputvoltage frequency and amplitude in function of the active and reactive power delivered by the inverter. The droop method achieves higher reliability and flexibility in the physical location of the modules, since it uses only local power measurements. Nevertheless, the conventional droop method shows several drawbacks that limit its application area, such as slow transient response, tradeoff between the power-sharing accuracy and the frequency and voltage deviations, unbalance harmonic current sharing, and high dependency on the inverter output impedance. In addition, the line impedance is unknown, which can result in reactive power unbalances. This problem can be overcome by injecting high-frequency signals through the power lines or by adding external data communication signals. These communication systems, typically digital, must not be critical and robust. This way, controller area networks, power line communications, or wireless (radio frequency links) are often implemented [75]-[78].

In this paper, a review of the control schemes for the parallel operation of UPS systems and the trends of these systems in DG systems and microgrids are presented. Although the control of standalone UPS inverters was widely studied, it will not be shown in this paper [79]-[86]. This paper is organized as follows. Section II describes the configuration types of distributed UPS systems. Section III analyzes the circulating current problem derived from the parallel operation of UPS inverters. Section IV depicts the active load-sharing techniques, including centralized control, MS control, ALS, and 3C. Section V provides the description of the conventional droop control method, including a power flow analysis. Then, a generalization of the droop method, the virtual impedance loop approach, and the multiloop droop control techniques are described. Finally, in Section VI, a comparison between the control techniques and the conclusions is provided.

\section{Configurations of Distributed UPS Systems}

Distributed UPS systems support UPS units and critical loads flexibly located in an interconnected electrical power network. In order to add reliability and expandability to the system, redundant and parallel UPS systems are usually integrated into the power system. There are two major types of distributed UPS systems (see Fig. 1), i.e., online and line-interactive distributed systems [47]. 


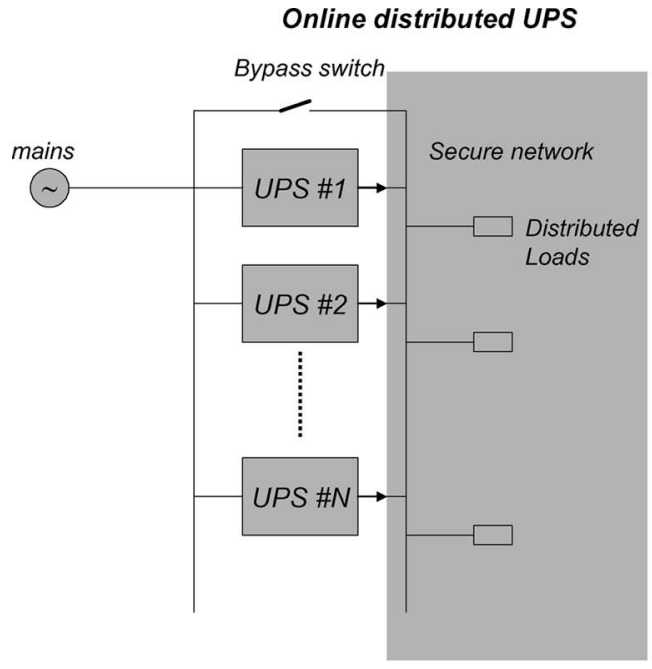

(a)

Fig. 1. Distributed UPS system configurations. (a) Online. (b) Line interactive.

The distributed UPS systems are highly reliable because of redundancy. It is an advantage to achieve the $N+1$ or $N+X$ redundancy in these systems, where $N$ UPS units supply the load, and 1 or $X$ additional units stay in reserve. They are also highly flexible to increase the capacity of the system when more power is needed, by simply adding more UPS units [21].

\section{A. Redundancy $N+1$ or $N+X$ UPS Units}

The redundancy concept consists of having one $(N+1)$ or more UPS units $(N+X)$ in reserve, and, if some of the rest of the $N$ modules are damaged or disconnected, this/these modules can automatically be connected to supply the functions of that unit. The redundancy can reduce the single point failure. A parallel redundant system can typically provide up to $99.99 \%$ availability, which means that the system does not operate for less than $1 \mathrm{~h} /$ year. In addition to having extra UPS modules, the parallel redundant system needs to give the operator some measure of system-level functionality. The simplest redundant UPS system is the $1+1$ parallel redundant, which consists of using a centralized UPS with one reserve module [19].

\section{B. Parallel Operation of UPS Systems}

The proper parallel operation of the $N$ modules that configure the distributed UPS system is crucial. Generally speaking, a paralleled UPS system must achieve the following features [5], [6]: 1) the same output-voltage amplitude, frequency, and phase; 2) equal current sharing between the units; 3 ) flexibility to increase the number of units; and 4) plug and play operation at any time, also known as hot-swap operation capability. The parallel operation of UPS has a number of advantages, including thermal management, reliability, redundancy, modularity, maintainability, and size reduction.

\section{Circulating Current Analysis}

The output currents of each UPS should be equal or at least proportional to its nominal power rating. The difference

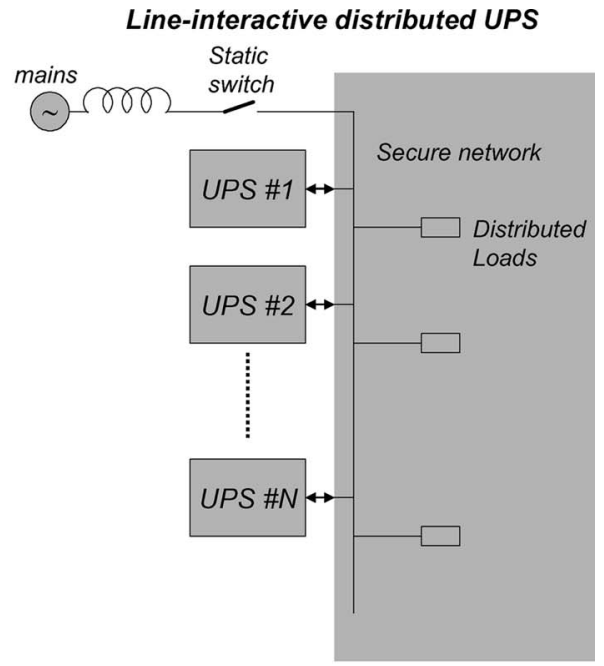

(b)

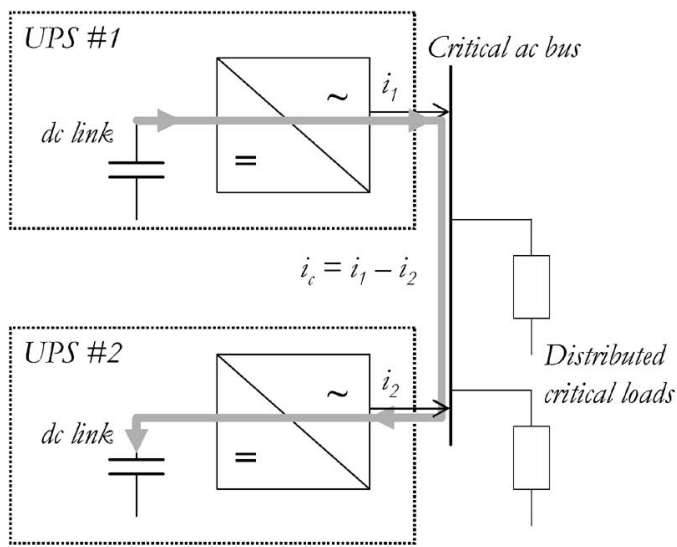

Fig. 2. Circulating current concept.

between those currents provokes circulating currents among the UPS units. The circulating current $\left(i_{c}\right)$ is particularly dangerous at no-load or light-load conditions, since one or several modules can absorb active power operating in rectifier mode, as shown Fig. 2. This current increases the dc-link voltage level, which can result in damage to the dc-link capacitors or in a shutdown due to overload [24].

An analysis of the circulating current can be done by using the equivalent circuit of two UPS units connected in parallel, sharing a common load. The analysis presented in this section will be made using phasors, being only valid under sinusoidal conditions. Following Fig. 3, we can define the circulating apparent power as

$$
\Delta S \triangleq S_{1}-S_{2}
$$

and, consequently, the active and reactive circulating powers are

$$
\begin{aligned}
& \Delta P \triangleq P_{1}-P_{2} \\
& \Delta Q \triangleq Q_{1}-Q_{2} .
\end{aligned}
$$

Assuming that $L_{1} \gg Z_{o 1}+Z_{L 1}, L_{2} \gg Z_{o 2}+Z_{L 2}$, and that the total output impedance $X_{T}\left(L_{1}+L_{2}\right)$ is mainly inductive, 


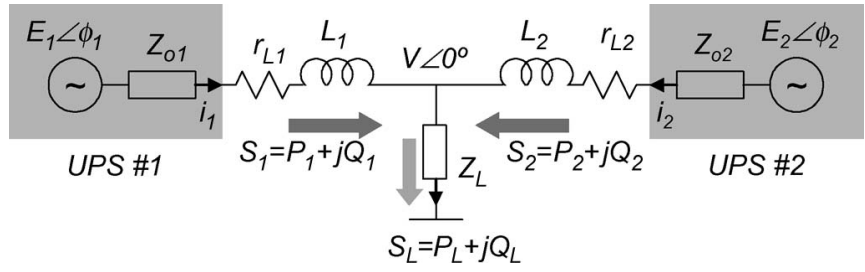

Fig. 3. Equivalent circuit of two UPSs connected in parallel, taking into account the output impedance of the inverters $\left(Z_{o 1}\right.$ and $\left.Z_{o 2}\right)$ and the power line impedances $\left(\vec{Z}_{L 1}=r_{L 1}+j \omega L_{1}\right.$ and $\left.\vec{Z}_{L 2}=r_{L 2}+j \omega L_{2}\right)$.

then (2) and (3) can be simplified as

$$
\begin{aligned}
& \Delta P \cong \frac{E_{1} E_{2}}{X_{T}} \sin \Delta \phi \cong \frac{E_{1} E_{2}}{X_{T}} \Delta \phi \\
& \Delta Q \cong \frac{V}{X_{T}} \Delta E
\end{aligned}
$$

where $\Delta \phi=\phi_{1}-\phi_{2}$, and $\Delta E=E_{1}-E_{2}$.

Thus, these equations can be expressed in function of the currents instead of the power, being the active and reactive circulating currents, as

$$
\begin{aligned}
& \Delta i_{P} \cong \frac{E_{1} E_{2}}{V X_{T}} \Delta \phi \\
& \Delta i_{Q} \cong \frac{\Delta E}{X_{T}} .
\end{aligned}
$$

In conclusion, assuming an inductive output impedance, the active and reactive powers or currents can be controlled by adjusting the phase and amplitude of the output voltage.

In order to try to avoid the circulating current, there exist a number of control strategies that can be classified in active loadsharing and droop control techniques, depending on the use or not of communication links between UPS units.

\section{Active LOAD SHARING}

The first kind of control scheme, named the active loadsharing technique, needs intercommunication links. Although these links limit the flexibility of the UPS system and degrade its redundancy, both tight current sharing and low-outputvoltage total harmonic distortion (THD) can be achieved. The following section provides a review of the existing techniques for paralleling inverters available in the literature. The active load-sharing techniques can be classified into four different types, i.e., centralized control [22], [23], MS [24]-[32], ALS [33]-[41], and 3C [42], [43]. Using these techniques, we will generate the current or power reference of each module, which is easy to scale according to its nominal power rating.

\section{A. Centralized Control}

This control technique, also known as concentrated control, is depicted in Fig. 4. It consists of dividing the total load current $i_{L}$ by the number of modules $N$, so that this value becomes the current reference $\left(i_{j}^{*}\right)$ of each module $j$ [22], [23]

$$
i_{j}^{*}=\frac{i_{L}}{N}, \quad \text { for } \quad j=1, \ldots, N \text {. }
$$

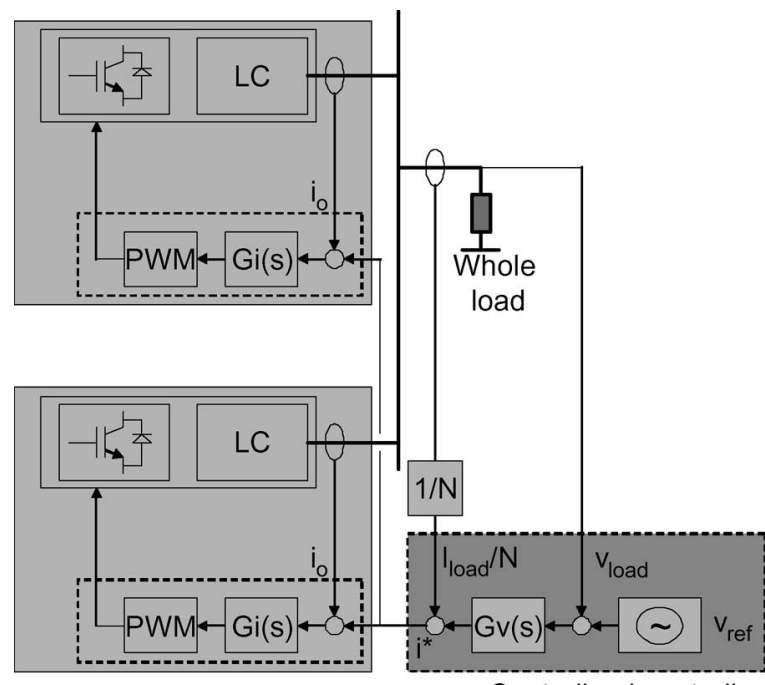

Centralized controller

Fig. 4. Block diagram of a centralized controller for paralleled UPS system.

The current reference value is subtracted by the current of each module, obtaining the current error $\Delta I_{j}$, which is processed through a current control loop.

An outer control loop in the centralized control adjusts the load voltage. This system is normally used in common UPS equipment with several output inverters connected in parallel. Using this approach, it is necessary to measure the total load current $i_{L}$, so it cannot be used in a large distributed system. Consequently, a central control board is necessary.

The control implementation can follow two philosophies. The first one is expressed by (8), and the second is to calculate the current error $\Delta i=i_{j}^{*}-i_{j}$ and to decompose it in direct current error $\Delta i_{p}$ and in quadrature current error $\Delta i_{q}$. Finally, $\Delta i_{p}$ and $\Delta i_{q}$ can be used to adjust the phase and amplitude of the output-voltage reference of each UPS unit. The other possibility is to use $\Delta i$ and the output voltage to calculate $\Delta P$ and $\Delta Q$ instead of $\Delta i_{p}$ and $\Delta i_{q}$, as shown in Fig. 5 [6].

\section{B. $M S$}

In this technique, the master module regulates the load voltage. Hence, the master current $i_{M}$ fixes the current references of the rest of the modules (slaves) as

$$
i_{S}^{*}=i_{M}, \quad \text { for } \quad S=2, \ldots, N \text {. }
$$

Consequently, as shown in Fig. 6, the master acts as a voltage source inverter (VSI), whereas the slave works as a current source inverter (CSI) [30]. In this configuration, if the master unit fails, another module will take the role of master in order to avoid the overall failure of the system. There exist different variants of this control scheme, depending on the role of the master.

1) Dedicated: the master is one fix module.

2) Rotary: the master is arbitrarily chosen.

3) High-crest current: the master can be fixed by the module that brings the maximum rms or crest current. Unitrode ICs, such as UC3902 or UC3907, are used to parallel $\mathrm{dc} / \mathrm{dc}$ converters, implementing the MS strategy in which 


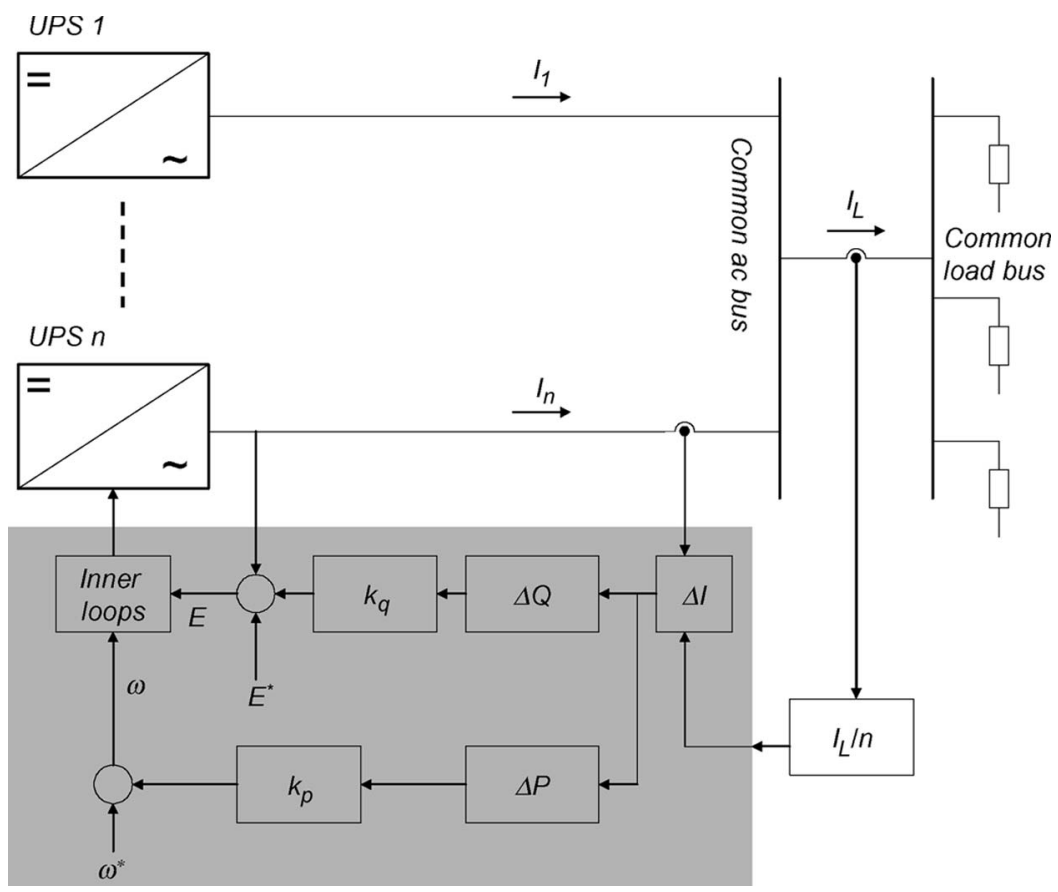

Fig. 5. Block diagram of a centralized controller based on active and reactive power deviation decomposition.

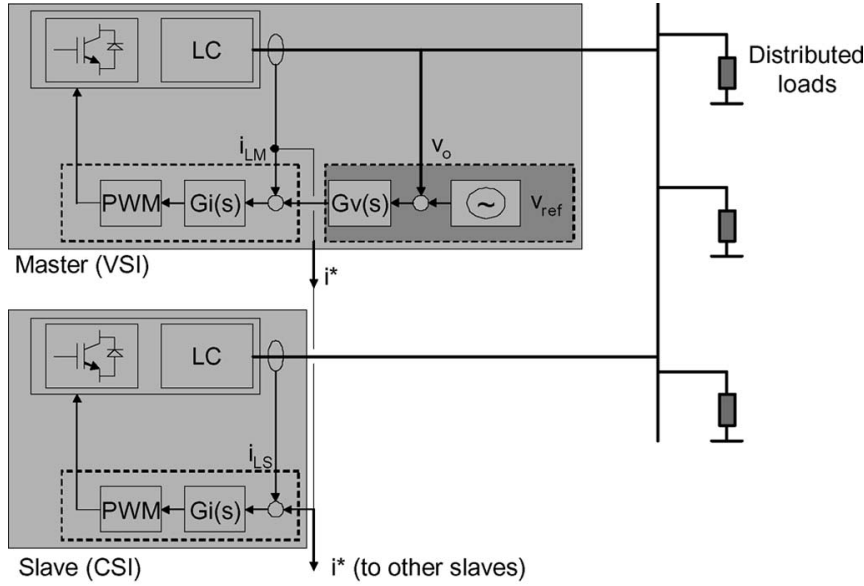

(a)

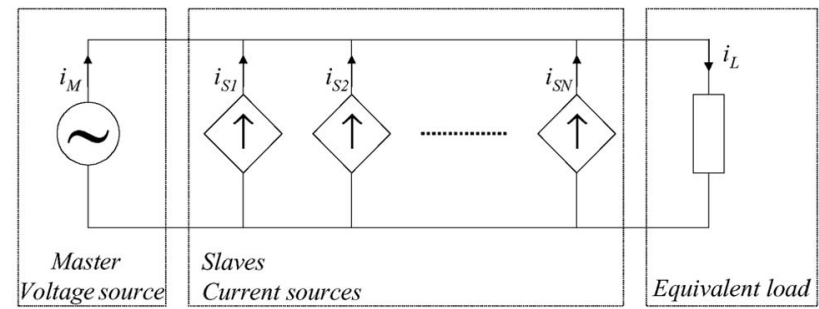

(b)

Fig. 6. MS control strategy. (a) Block diagram of the system. (b) Equivalent circuit of the parallel UPS system controlled through the MS strategy.

the module that brings the maximum current automatically becomes the master.

This strategy can also be implemented by using average active and reactive powers as

$$
\begin{array}{lll}
P_{S}^{*}=P_{M}, & \text { for } & S=2, \ldots, N \\
Q_{S}^{*}=Q_{M}, & \text { for } & S=2, \ldots, N .
\end{array}
$$

In this particular case, and by using the highest $P$ and $Q$ average values, a scheme similar to the high-crest current control strategy can be obtained. This control strategy is shown in Fig. 7, and in that case, the master UPS of $P$ and $Q$ can be different modules [28]. MS control is often adopted when using different UPS units mounted into a rack.

\section{C. $A L S$}

This is a true democratic control scheme in which every module tracks the average current done by all the active modules [33]-[41]. This scheme, shown in Fig. 8(a), is simple to implement by using a single wire, which contains the average current information computed by a resistor connected to the current sensor of every single module. In addition, adjusting the resistor to a proper value, we can parallel converters with different power rating. This control technique starts from an idea applied to parallel $\mathrm{dc} / \mathrm{dc}$ converters by using currentsharing resistors connected to a common information bus. The current of all modules is averaged by means of a common current bus. The average current of all the modules is the reference for each individual one. This control scheme is highly reliable due to the real democratic conception, in which no MS philosophy is present. In addition, the approach is highly modular and expandable, making it interesting for industrial UPS systems. In general, this scheme is the most robust and useful of the aforementioned controllers. A variant of this technique is the current weighting distribution control [39]. The current reference of each module can be expressed as

$$
i_{k}^{*}=\frac{1}{N} \sum_{j=1}^{N} i_{j}, \quad \text { for } \quad k=1, \ldots, N .
$$

This control approach can be performed by using an inner or an outer current loop. The problem with using an outer loop 


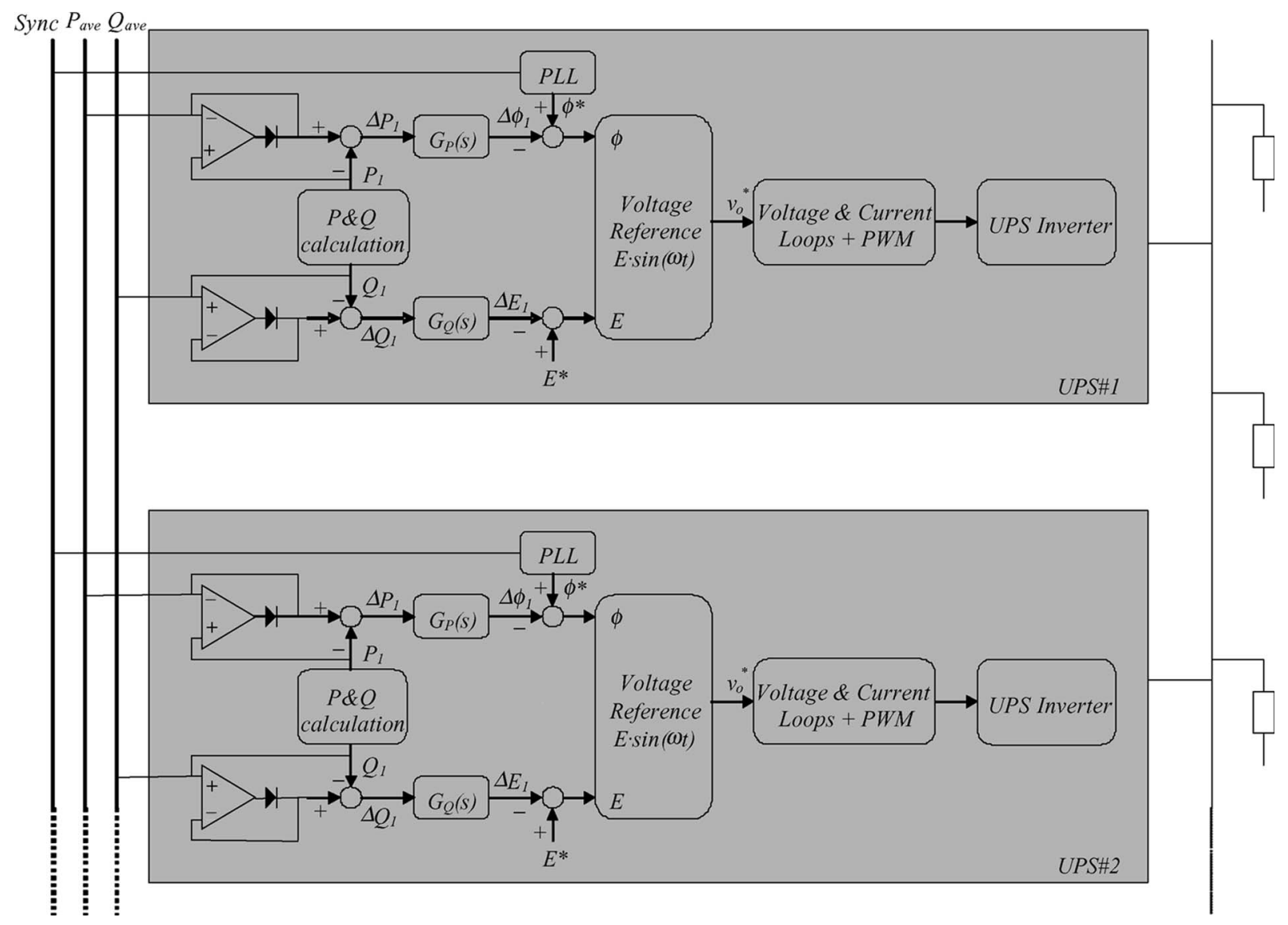

Fig. 7. Auto-MS (highest crest $P / Q$ master) power-sharing control scheme.

is that due to that, the voltage loop has a narrow bandwidth, and in order to avoid instabilities, the current loop needs a compensator. As a consequence of the bandwidth reduction of this loop, the current dynamics is very slow, provoking poor current sharing during transients.

As usual, another possibility is to use active and reactive power information instead of the current. Thus, we use active and reactive power to adjust the phase and amplitude of each module. Fig. 8(b) shows the block diagram of the average power-sharing technique [41]. Using this technique, each UPS unit controls the active and reactive power flow in order to match the average active and reactive powers of the system by adjusting the phase and the amplitude of its own inner output-voltage reference. The active and reactive power can be obtained through the direct and reactive component decomposition of the output current. The average active and reactive power references of each module can be expressed as

$$
\begin{aligned}
& P_{k}^{*}=\frac{1}{N} \sum_{j=1}^{N} P_{j} \\
& Q_{k}^{*}=\frac{1}{N} \sum_{j=1}^{N} Q_{j}, \quad \text { for } \quad k=1, \ldots, N .
\end{aligned}
$$

An earlier work uses this method to achieve the power sharing between two UPS modules [40]. This control scheme can be extended to more units by using the active and reactive average power-sharing buses. Notice that this technique does not require any master or slave unit, and only low-bandwidth digital communications are required to achieve good $P$ and $Q$ sharing. Nevertheless, it only acts over the fundamental component of the output current, misleading the harmonic content. Hence, unbalances between the power stages and the power lines can produce large circulating harmonic current between the units.

\section{D. $3 C$}

This control scheme, shown in Fig. 9, consists of the current reference of each module taken from the aforementioned module, forming a control ring [42]. Note that the current reference of the first unit is obtained from that of the last unit to form a circular chain connection. This strategy can be expressed through

$$
\begin{aligned}
& i_{1}^{*}=i_{N} \\
& i_{k}^{*}=i_{k-1}, \quad \text { for } \quad k=2, \ldots, N .
\end{aligned}
$$

The approach can be interesting for distributed power systems based on ac power rings due to the distribution of power lines [54]. Fig. 10 illustrates the example of a distributed ringforming UPS system. There are two lines in order to achieve bidirectional communication and to increase system reliability. 


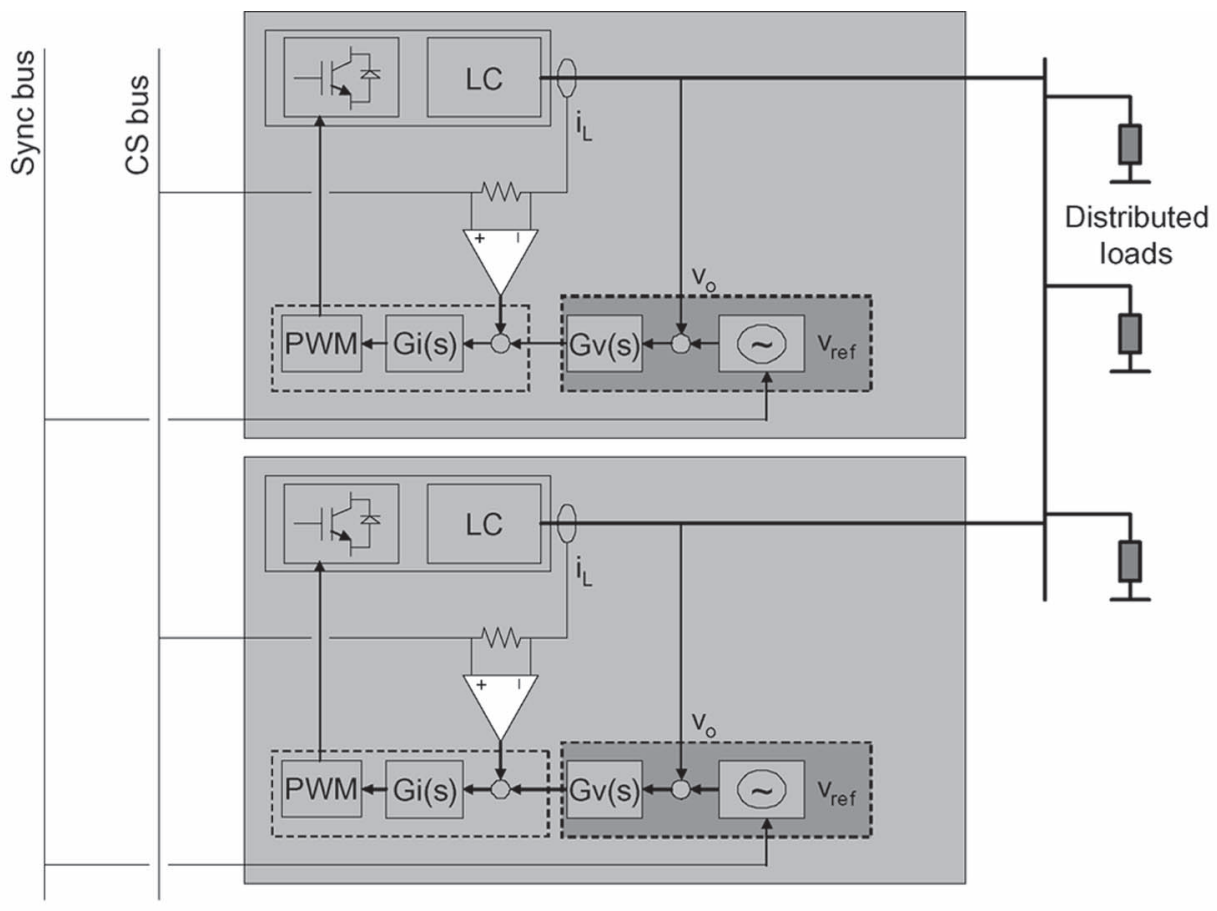

(a)

Sync $P_{\text {ave }} Q_{\text {ave }}$

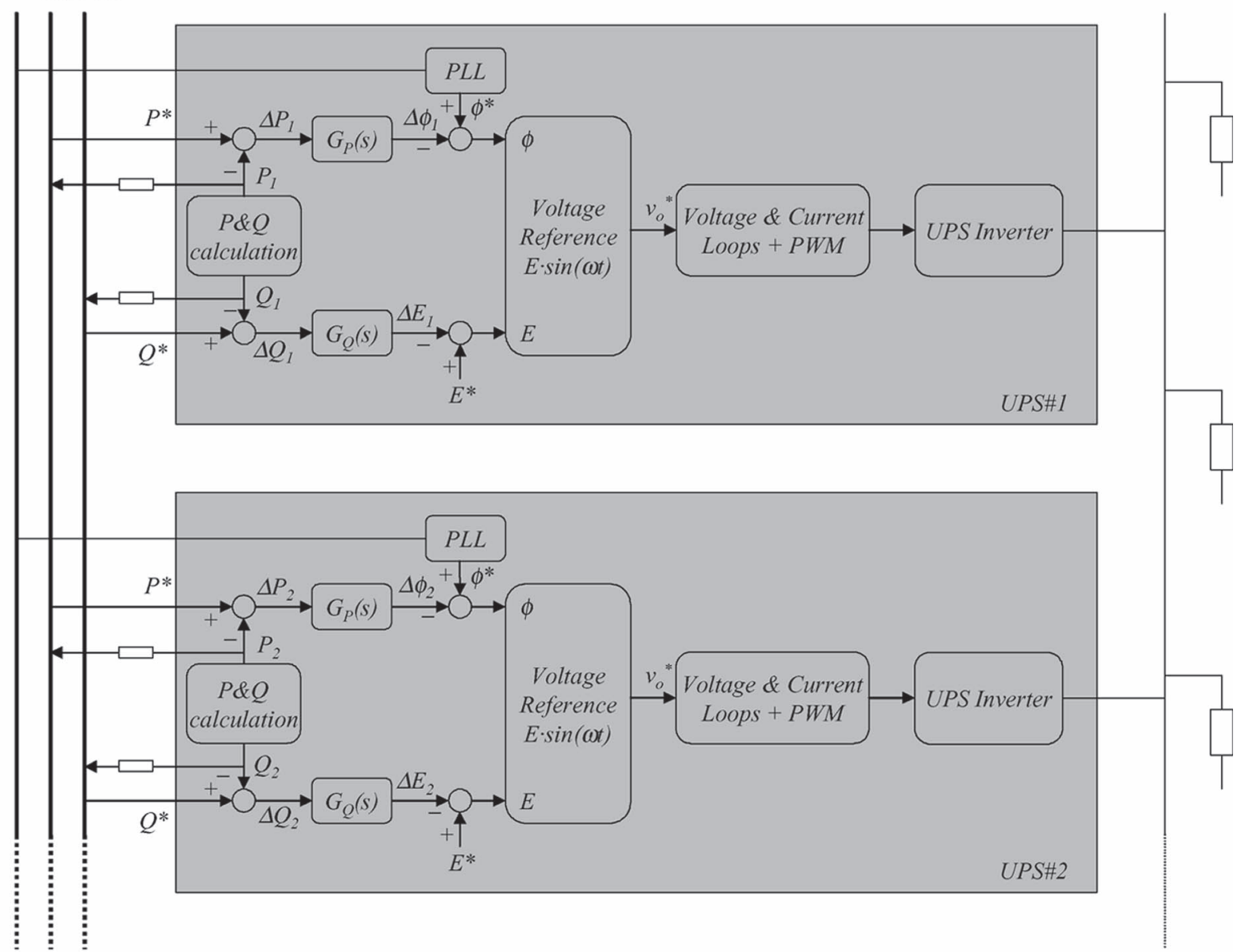

(b)

Fig. 8. ALS control schemes. (a) Average current sharing. (b) Average power sharing. 


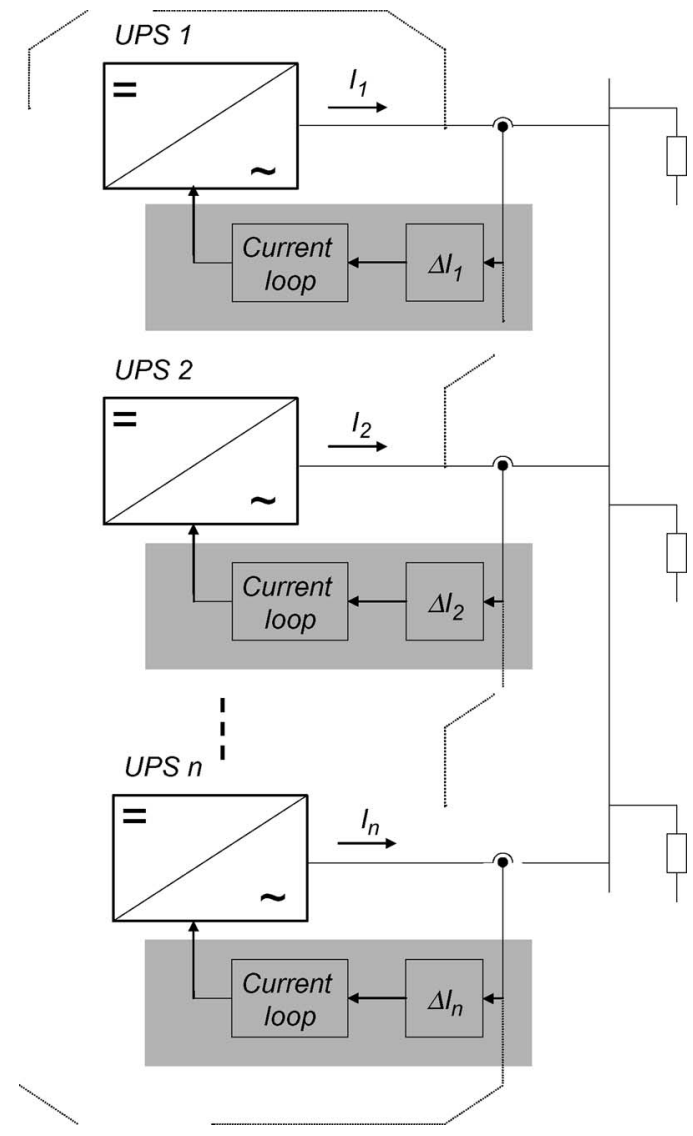

Fig. 9. Block diagram of the current chain control (3C).

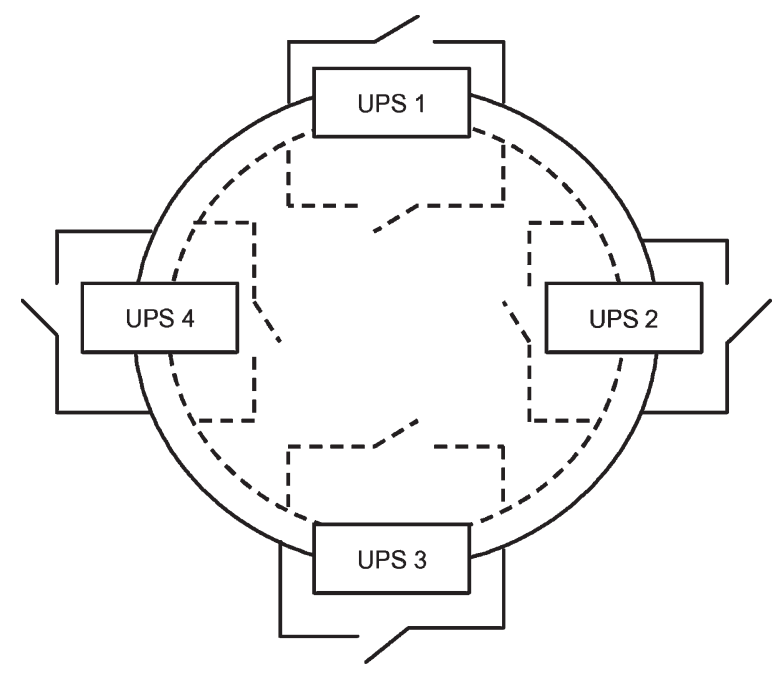

Fig. 10. Communication links of the current chain control (3C).

The current limitation control is a variant of the $3 \mathrm{C}$. In this case, the load voltage is controlled by the master module, whereas the slave modules are only for sharing the load current. Except for the master module, the current command of the slave is generated by its previous module and limited in amplitude [43]. In this scheme, any module can be the master (dedicated, rotating, or high-crest current). The connection of all control circuits can form a circular chain connection such that every module may become the master.

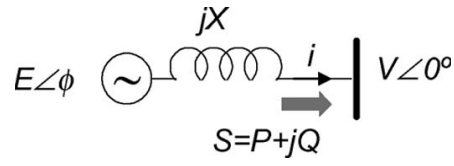

Fig. 11. Equivalent circuit of a UPS inverter connected to a common ac bus.

\section{Droop Control Method}

The second kind of control scheme, named the droop control method, is able to avoid critical communication links. The absence of critical communications between the modules improves the reliability without restricting the physical location of the modules [44]-[74].

In the literature, the droop method is also called independent, autonomous, or wireless control. The droop method is based on a well-known concept in large-scale power systems, which consists of drooping the frequency of the ac generator when its output power increases. In the case of parallel-connected UPS inverters, the active and reactive powers supplied to the ac bus are sensed and averaged, and the resulting signals are used to adjust the frequency and amplitude of the UPS inverter outputvoltage reference. The droop method achieves higher reliability and flexibility in the physical location of the modules since it only uses local power measurements.

\section{A. Active and Reactive Power Droop Control}

Traditionally, the inverter output impedance is considered to be inductive due to the high inductive component of the line impedance and the large inductor filter. Fig. 11 shows the equivalent circuit of an inverter connected to a common coupling point through an inductance. In this situation, the following well-known expressions of active and reactive powers can be derived and simplified by considering a small phase difference $\phi$ between the inverter output voltage $E$ and the common ac bus voltage $V(\sin \phi \approx \phi$ and $\cos \phi \approx 1)$ :

$$
\begin{aligned}
& P=\frac{E V}{X} \sin \phi \approx \frac{E V}{X} \phi \\
& Q=\frac{E V \cos \phi-V^{2}}{X} \approx \frac{V}{X}(E-V)
\end{aligned}
$$

where $X$ is the output reactance of the inverter.

From these equations, we can conclude that $P$ increases with the phase angle and $Q$ with the amplitude difference $(E-V)$. Hence, if we want a negative feedback, then we need to reduce $\phi$ and $E$ when $P$ and $Q$ increase. Consequently, one solution is to introduce artificial droops into the output-voltage reference. Thus, $P-\omega$ and $Q-V$ droop schemes are often adopted. Fig. 12 shows the block diagram of the conventional droop control scheme. The simplest form to implement the control law can be expressed as follows [46]:

$$
\begin{aligned}
& \omega=\omega^{*}-m\left(P-P^{*}\right) \\
& E=E^{*}-n\left(Q-Q^{*}\right)
\end{aligned}
$$




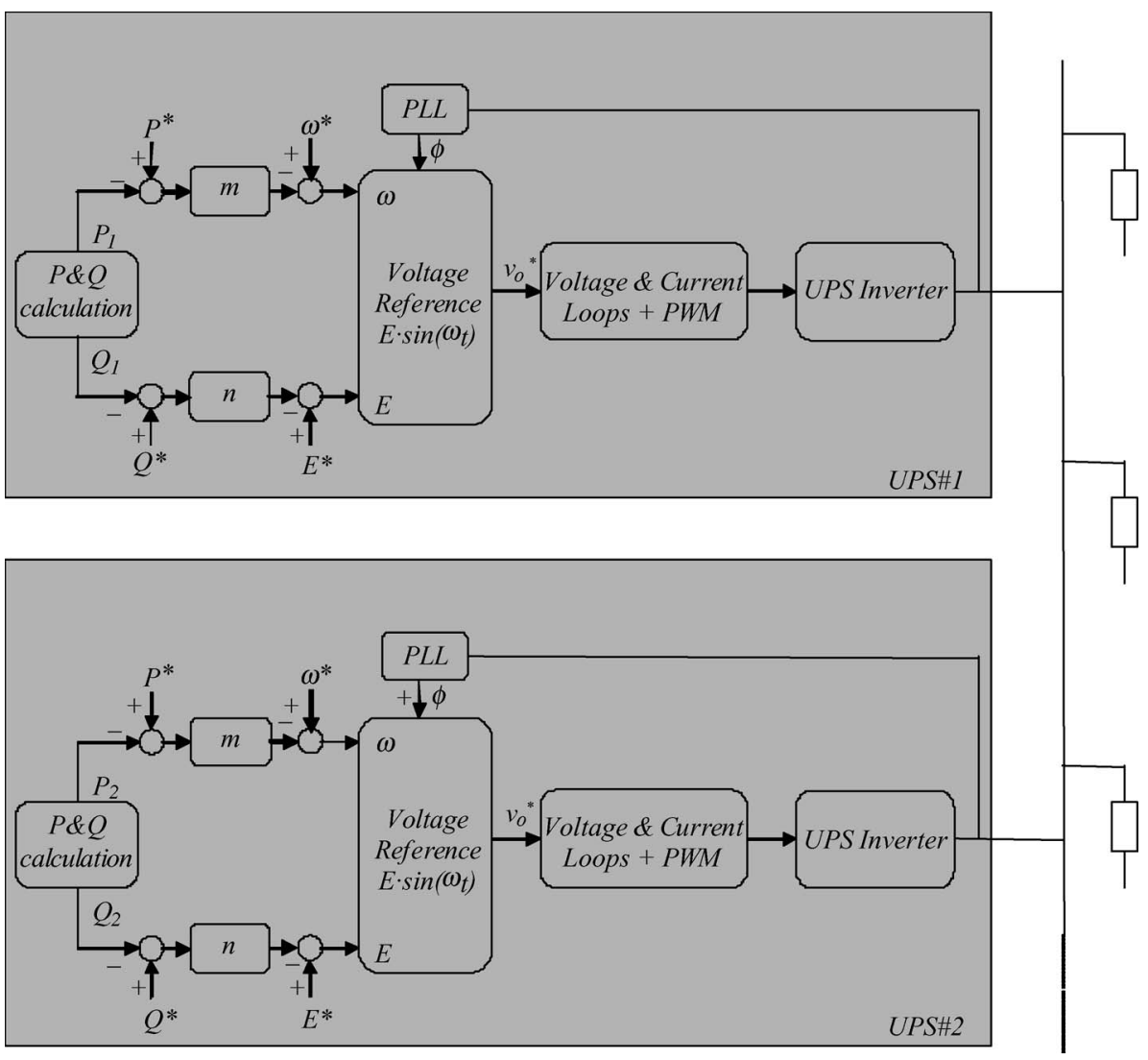

Fig. 12. Block diagram of the conventional power-sharing droop method.

where $\omega^{*}$ and $E^{*}$ are the output-voltage frequency and amplitude at no load, and $m$ and $n$ are the droop frequency and amplitude coefficients. $P^{*}$ and $Q^{*}$ are the active and reactive power references, which are commonly set to zero $\left(P^{*}=0\right.$ and $Q^{*}=0$ ) when we connect UPS units in parallel, autonomously forming an energetic island. However, if we want to share power with a constant power source, e.g., the utility grid, we should fix the active and reactive powers to be drawn from the unit.

Notice that although (17) shows a relationship between $\phi$ and $P,(19)$ uses frequency $(\omega)$ instead of $\phi$. This is because the units do not know the initial phase value of the other units; however, the initial frequency at no load can easily be fixed as $\omega^{*}$. In fact, it is necessary to compensate the difference between the crystal clock generators. This is the reason why trying to remove the frequency deviation through an integrator is not a long-time stable solution [47]. The frequency restoration must externally be done or, in an online double-conversion UPS system, through the utility grid when it is present.

Using this method, it is well known that if the droop coefficients are increased, then good power sharing is achieved at the expense of degrading the voltage regulation, which can be acceptable if, for instance, the frequency and amplitude deviations are mostly at $2 \%$ and $5 \%$, respectively. In fact, $m$ and $n$ are designed from (19) and (20) by using

$$
\begin{aligned}
m & =\delta \omega / P_{\max } \\
n & =\delta e / 2 Q_{\max }
\end{aligned}
$$

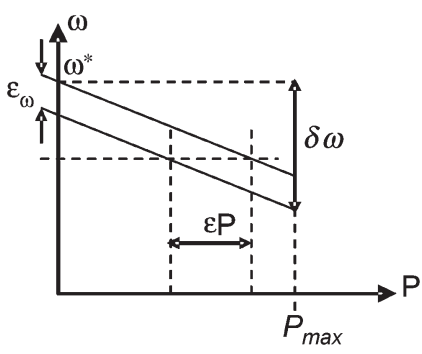

Fig. 13. Tradeoff for design $P-\omega$ droop coefficient.

where $\delta \omega$ and $\delta e$ are the maximum allowed frequency and voltage deviation, and $P_{\max }$ and $Q_{\max }$ are the nominal $P$ and $Q$ provided by the UPS. This way, the $P$ and $Q$ sharing errors [(2) and (3)] in steady state are done by the error of frequency $\varepsilon_{\omega}$ and voltage $\varepsilon_{E}$ as

$$
\begin{aligned}
\varepsilon_{P} & =\varepsilon_{\omega} / m \\
\varepsilon_{Q} & =\varepsilon_{E} / n
\end{aligned}
$$

where $\varepsilon_{P}$ and $\varepsilon_{Q}$ are the steady-state active and reactive power differences, and $\varepsilon_{\omega}$ and $\varepsilon_{E}$ are the differences in frequency and amplitude between the inverters.

As can be seen, $\varepsilon_{P}$ and $\varepsilon_{Q}$ can be reduced by increasing $m$ and $n$, but the limited by (21) and (22). Fig. 13 illustrates the tradeoff for the case of the $m$ coefficient. Note that the power-sharing error depends on the frequency error but not in the inherent frequency deviation. 
TABLE I

OUtPut IMPEDANCE IMPACT OVER POWER FLOW CONTROLLABILITY

\begin{tabular}{|c|c|c|}
\hline $\begin{array}{c}\text { Output } \\
\text { impedance }\end{array}$ & $\begin{array}{c}Z=j X \\
\left.\text { (inductive: } \theta=90^{\circ}\right)\end{array}$ & $Z=R$ (resistive: $\left.\theta=0^{\circ}\right)$ \\
\hline $\begin{array}{c}\text { Active } \\
\text { power }(P)\end{array}$ & $P=\frac{E V}{X} \sin \varphi \cong \frac{E V}{X} \varphi$ & $P=\frac{E V \cos \varphi-V^{2}}{R} \cong \frac{V}{R}(E-V)$ \\
\hline $\begin{array}{c}\text { Reactive } \\
\text { power }(Q)\end{array}$ & $Q=\frac{E V \cos \varphi-V^{2}}{X} \cong \frac{V}{X}(E-V)$ & $Q=\frac{E V}{R} \sin \varphi \cong-\frac{E V}{R} \varphi$ \\
\hline $\begin{array}{c}\text { Frequency } \\
\text { droop }(\omega)\end{array}$ & $\omega=\omega^{*}-m P$ & $\omega=\omega^{*}+m Q$ \\
\hline $\begin{array}{c}\text { Amplitude } \\
\text { droop }(E)\end{array}$ & $E=E^{*}-n Q$ & $E=E^{*}-n P$ \\
\hline$m$ & $\delta \omega / P_{\text {nom }}$ & $\delta \omega / 2 Q_{\text {nom }}$ \\
\hline$n$ & $\delta E / 2 Q_{\text {nom }}$ & $\delta E / P_{\text {nom }}$ \\
\hline
\end{tabular}

When units of different rating are connected in parallel, the droop coefficient values have to be adjusted according to the following relationships [46]:

$$
\begin{gathered}
m_{1} S_{1}=m_{2} S_{2}=\cdots=m_{N} S_{N} \\
n_{1} S_{1}=n_{2} S_{2}=\cdots=n_{N} S_{N}
\end{gathered}
$$

where $S_{i}$ is the apparent power of the UPS $i$.

Usually, the inverter output impedance is considered to be inductive, which is often justified by the high inductive component of the line impedance and the large inductor of the output filter. However, this is not always true, since the closed-loop output impedance also depends on the control strategy, and the line impedance is predominantly resistive for low voltage cabling. The output impedance of the closed-loop inverter affects the power-sharing accuracy and determines the droop control strategy. Thus, (17) and (18) can be recalculated by considering a general output impedance of each inverter $Z \angle \theta$. The active and reactive powers injected to the bus by every unit can be expressed as

$$
\begin{aligned}
& P=\left(\frac{E V}{Z} \cos \phi-\frac{V^{2}}{Z}\right) \cos \theta+\frac{E V}{Z} \sin \phi \sin \theta \\
& Q=\left(\frac{E V}{Z} \cos \phi-\frac{V^{2}}{Z}\right) \sin \theta-\frac{E V}{Z} \sin \phi \cos \theta
\end{aligned}
$$

where $E$ and $V$ are the amplitudes of the inverter output voltage and the common bus voltage, $\phi$ is the power angle, and $Z$ and $\theta$ are the magnitude and phase of the output impedance, respectively. Notice that there is no decoupling between $P-\phi$ and $Q-E$.

Consequently, we can rewrite the droop control method in general form as [67]

$$
\begin{aligned}
& \omega=\omega^{*}-m(P \sin \theta-Q \cos \theta) \\
& E=E^{*}-n(P \cos \theta+Q \sin \theta) .
\end{aligned}
$$

The output impedance angle $\theta$ determines the droop control law, as shown in Table I. Fig. 14 shows the droop control functions depending on the output impedance. The controller gains $m$ and $n$ are chosen as a function of the nominal values of $P$ and $Q$, and the maximum allowed deviations in frequency $\delta \omega$ and amplitude $\delta E$ (Table I).

\section{B. Virtual Output Impedance: The Multiloop Approach}

It is known that the line impedance has a considerable effect on the power-sharing accuracy of the $P / Q$ droop method. Alternatively or complementary to the use of signal communications, it is often used as a fast control loop, called virtual output impedance, which can be used to fix the output impedance of the inverter.

This impedance should be larger than the combined values of the output impedance of the UPS inverter plus the maximum power line impedance. The implementation of the virtual output impedance can by done by using the following expression [66]:

$$
v_{o}=v_{o}^{*}-i_{o} Z_{o}(s)
$$

where $Z_{o}(s)$ is the transfer function of the virtual output impedance, $v_{o}^{*}$ is the voltage reference calculated by the $P / Q$ sharing loop, and $v_{o}$ is the output voltage provided to the inner control loops. Fig. 15 shows the block diagram of a droop controller with the virtual output impedance loop. The output impedance value must be selected following a similar way as the $m$ and $n$ coefficients, according to the nominal apparent power $S_{i}$ of each UPS unit $i$, i.e.,

$$
Z_{o 1} S_{1}=Z_{o 2} S_{2}=\cdots=Z_{o N} S_{N}
$$

At this point, we should bear in mind that the output impedance has become a control variable of our system.

Another practical issue is the desirable hot-swap or plug " $n$ " play capability, which consists of the seamless operation of the UPS inverter when it is suddenly connected to the common ac bus. The output current peak in such a situation is expressed as [65]

$$
I_{\mathrm{pk}} \approx \frac{E}{X} \cdot \Delta \phi
$$

where $\Delta \phi$ is the phase-locked-loop (PLL) phase error.

In order to reduce this initial current peak, we can reduce the PLL error to a limited small angle, but this is still not enough because this error is difficult to control due to the fact that the PLL accuracy depends on the sensor errors and on other nonideal parameters. Bearing in mind that the output impedance is a new adjustable control parameter, by following (33), we can deduce that another way to reduce the current peak is to increase the output inductance $L_{D}$. Hence, a softstart operation of the output impedance is proposed to alleviate this initial transient peak, achieving a seamless connection of the inverter to the common bus (hot-swap operation) [67] as

$$
L_{D}^{*}=L_{D f}^{*}+\left(L_{D o}^{*}-L_{D f}^{*}\right) e^{-t / T_{\mathrm{ST}}}
$$

where $L_{D o}^{*}$ and $L_{D f}^{*}$ are the initial and final values of the output impedance, and $T_{\mathrm{ST}}$ is the time constant of the soft-start operation. The soft-start operation proposed here consists of connecting the inverter to the common bus using a high output impedance and reducing it slowly toward the nominal value, as shown in Fig. 16. This way, the initial current peak can be avoided in spite of the PLL error. 

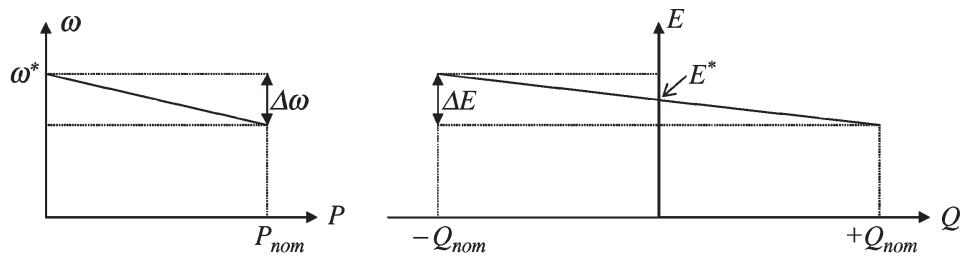

(a)
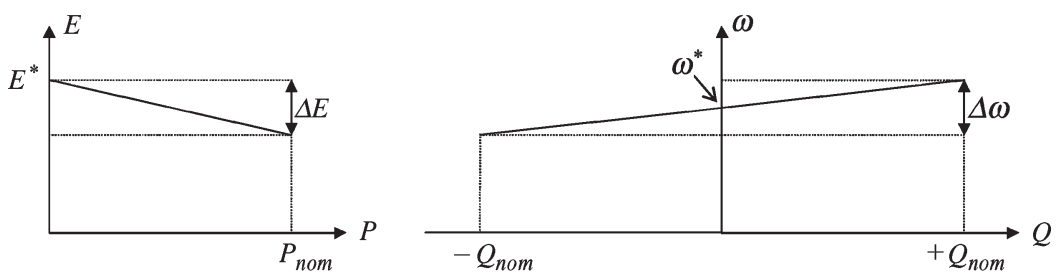

(b)

Fig. 14. Droop control functions for (a) inductive output impedance and (b) resistive output impedance.

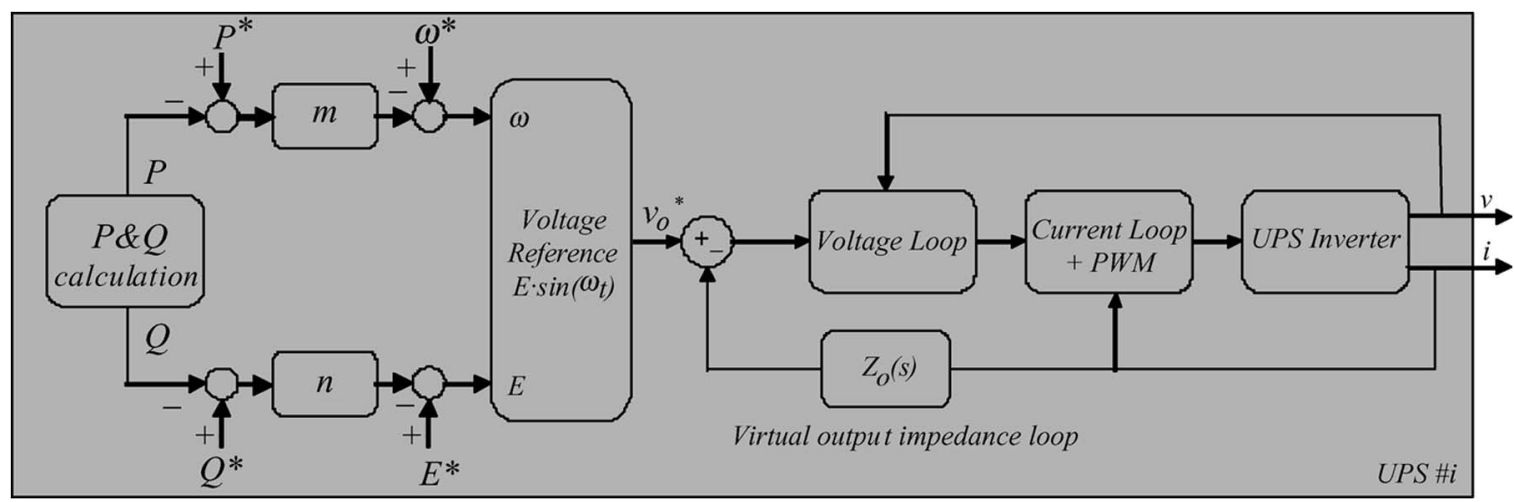

Fig. 15. Block diagram of the closed-loop system with the virtual output impedance path.

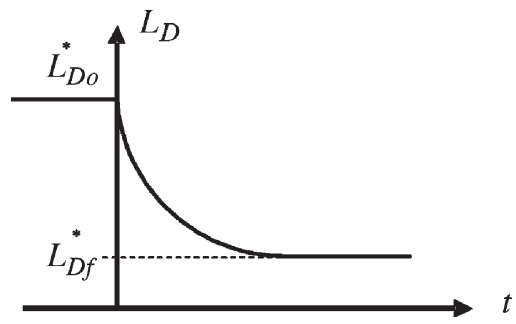

Fig. 16. Output inductance for the soft-start operation.

In addition, to prevent the increase of the dc-link voltage produced by the circulating currents, protective control algorithms have been proposed [70]. Fig. 17 shows the regeneration protection concept, which is based on the rising dc-link voltage. If this voltage rises over the reference value, the battery converter stops delivering power from the battery side. A proportional controller detects the error signal of the dc-link voltage. The control algorithm increases the sine reference value of this inverter module to stop this energy feedback.

\section{Harmonic Current Sharing}

The current THD in typical nonlinear loads can be up to $150 \%$, i.e., the sum of the harmonic current rms values can be up to 1.5 times the fundamental harmonic component. Hence, the UPS modules must be able to share these harmonics. This fact motivates the harmonic current sharing when supplying nonlinear loads.

The distorted power can be obtained from the apparent power $S$, active power $P$, and reactive power $Q$ by using the following expression:

$$
D=\sqrt{S^{2}-P^{2}-Q^{2}} .
$$

This expression, described in [48], obtains the apparent power value $S$ through the rms value of the instantaneous power, subtracts the square root values of $P$ and $Q$, and calculates the square root, obtaining the distorted power $D$.

Fig. 18 shows a controller that was proposed to share nonlinear loads by adjusting the output-voltage bandwidth with the delivered harmonic power [48]. This can be done by proportionally increasing the output-voltage loop gain to $D$, and hence, the bandwidth is reduced. As a consequence, the output impedance in the high-frequency range is increased, and the harmonic power sharing is automatically done. Nevertheless, this control strategy uses a complicated algorithm to calculate the harmonic current content, i.e., it uses three square calculations and a square root. Another important drawback is that the harmonic current sharing is achieved at the expense of reducing the stability of the system.

In another approach [55], every single term of the harmonic current is used to produce a proportional droop into the 


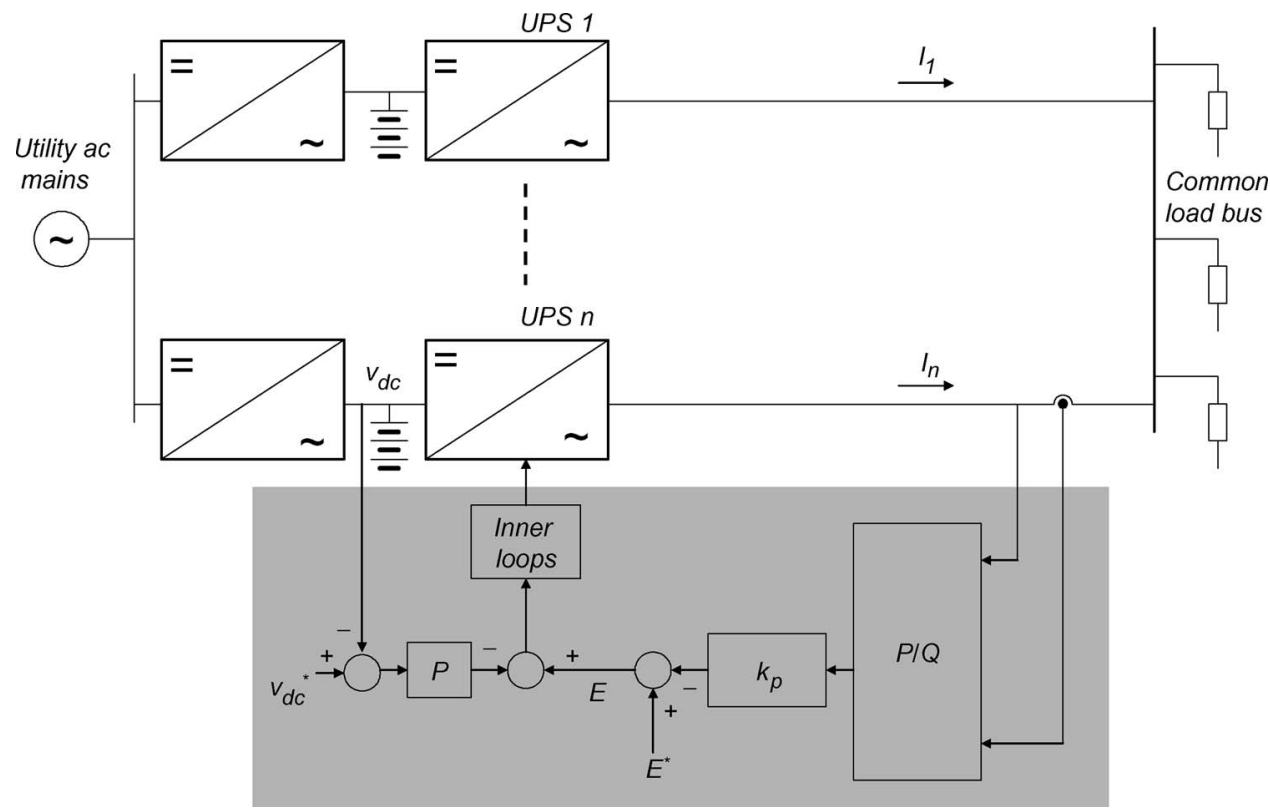

Fig. 17. Regenerative control structure to avoid dc-link overvoltage.

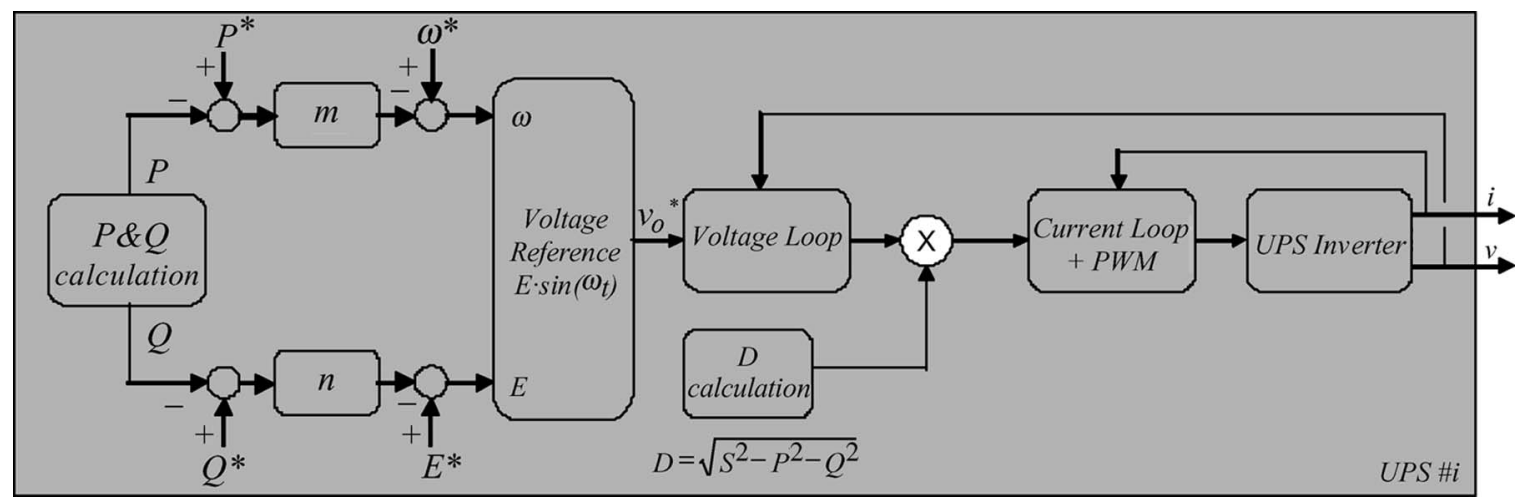

Fig. 18. Distorted power sharing by adjusting bandwidth.

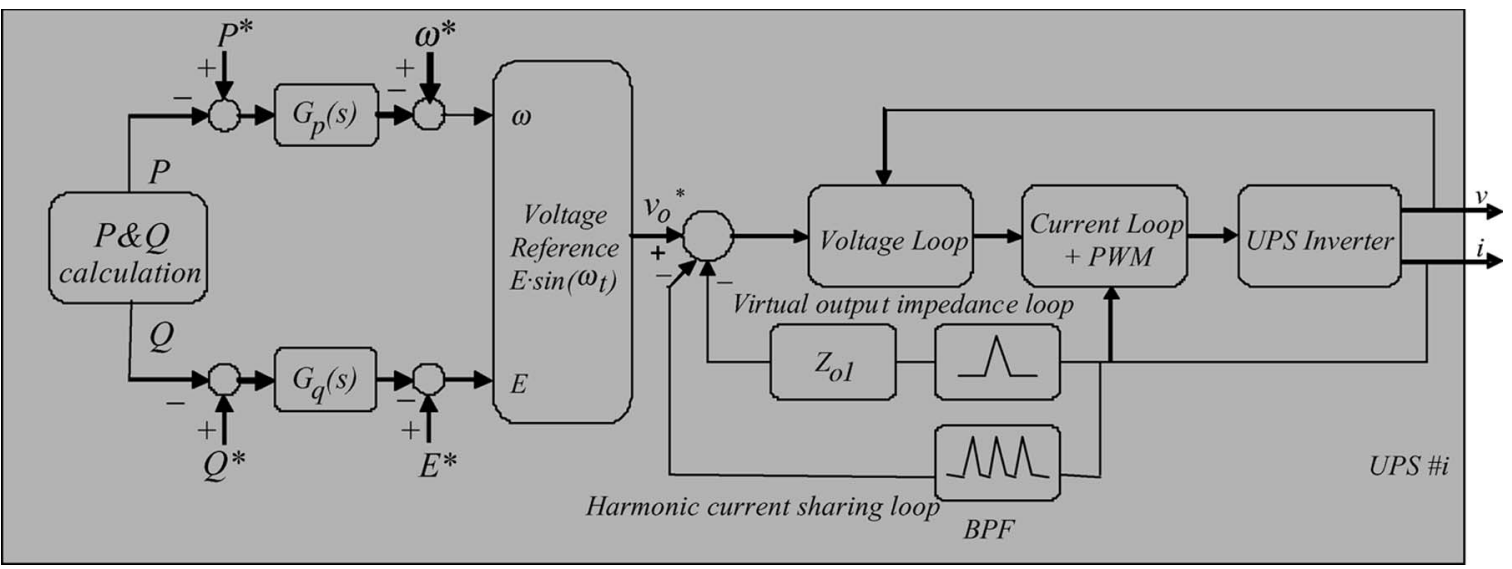

Fig. 19. Droop $P / Q$ sharing with instantaneous harmonic current-sharing loop.

corresponding harmonic voltage term, which is added to the output-voltage reference. In a similar way, it was proposed to adjust the resonant terms of a bank of generalized integrators in the control loop in function of each harmonic current value [78].
In addition, the harmonic current sharing can also be obtained through the virtual output impedance approach, in which the value of the harmonic component can be independently adjusted by means of a bank of bandpass filters. Fig. 19 shows this kind of multiple-loop droop control implementation [67]. 
TABLE II

ACtive Load Sharing Versus Droop Method Controllers

\begin{tabular}{|l|c|c|c|}
\hline \multicolumn{1}{|c|}{ Features } & $\begin{array}{c}\text { Active Current } \\
\text { Sharing }\end{array}$ & $\begin{array}{c}\text { Active Power } \\
\text { Sharing }\end{array}$ & $\begin{array}{c}\text { Droop } \\
\text { Method }\end{array}$ \\
\hline \# Control signals & $\begin{array}{c}\text { 1 synch }+ \\
\text { CS/2 PS bus }\end{array}$ & $\begin{array}{c}1 \text { synch + 2 PS } \\
\text { bus }\end{array}$ & 0 or low BW \\
\hline$V_{o}$ THD & Low & Low & Medium \\
\hline Harmonic CS & High & Low & Low \\
\hline Dynamics & Fast & Slow & Slow \\
\hline $\begin{array}{l}\text { Tradeoff } \\
\text { Regulation/CS }\end{array}$ & Low & Low & High \\
\hline Modularity & Medium & Medium & High \\
\hline Redundancy & Medium & Medium & High \\
\hline
\end{tabular}

CS: current sharing, PS: power sharing

\section{Communications}

The droop method does not need any communication link between the UPS inverters. This can be interesting when having islanded inverters that have to share the total load. However, it has several problems when trying to apply to the following.

1) Online distributed UPS system: In this case, the UPS inverters must be synchronized in phase with the utility mains when present. One additional loop can adjust the frequency and phase in a PLL fashion. Communications can reduce this problem. Furthermore, little measurement phase errors result in large circulating current between the inverters. In addition, it is necessary to communicate to the UPS units if one of the static bypass switches is turned on, among other emergency settings.

2) Line-interactive distributed UPS system: When the utility mains is disconnected, the UPS units have good balance; however, they must be resynchronized to the utility grid when the fault is cleared. Some authors propose just waiting to match the grid phase or to overload the UPS unit more closed to the utility switch. Both solutions are not reliable, and hazards can make the system shut down.

3) Large-area UPS system: In applications like a microgrid, the units can be located at distant points. Consequently, the power lines can be highly unbalanced, and the measurement errors can contribute to produce high circulating currents.

All these problems can be overcome by using communications. Combining low-bandwidth communications with the droop method can be a high-performance solution for a true distributed UPS system.

\section{PERFormance COMPARISON AND CONCLUSION}

In this paper, the control schemes for parallel UPS systems have been described, and their outstanding features are shown in Table II, including active load sharing and droop method. In general, active load-sharing control can be split into two main groups, i.e., current- and power-sharing control. The active current-sharing control achieves both good current-sharing and output-voltage regulation. However, it needs high-speed communications, since the current information must be processed by high-bandwidth control loops. On the other hand, by using active power-sharing techniques, the average active and reactive power information must be shared between local controllers.
TABLE III

VOLTAGE CONTROL LOOP FOR ACTIVE LOAD-SHARING CONTROLLERS

\begin{tabular}{|c|c|c|c|c|}
\hline Voltage loop & Centralized & $M S$ & $A L S$ & $3 C$ \\
\hline Common & $\checkmark$ & $\checkmark$ & $=$ & $=$ \\
\hline Distributed & $x$ & $x$ & $\checkmark$ & $\checkmark$ \\
\hline
\end{tabular}

In this case, low-bandwidth communications are enough, since these signals are averaged over one line cycle. However, the harmonic component is not reflected on the active and reactive powers. Thus, the harmonic power sharing is poor, which can be a problem when sharing nonlinear loads with a high crest factor. Active load-sharing techniques also require for the outputvoltage reference phase signal (which can be achieved by a dedicated line or by using a PLL circuit to synchronize all UPS modules). In a typical UPS application, the reference voltage is either synchronized with the external bypass utility line or, when this is not present, with an internal oscillator signal.

Active load-sharing techniques have been classified into four main groups, i.e., centralized control, MS, ALS, and 3C. The centralized control is simple and stable, obtaining an excellent current sharing. However, it has low reliability and redundancy. In addition, the controller needs to know the total number of active units and to sense the total load current to supply. Thus, a distributed power system cannot be managed by this controller, which is suitable for UPS systems with parallel output inverters inside the same equipment. The MS control has good currentsharing capability and stability. Although the reliability of the system can be improved by using a rotating master strategy, it makes its control and management complicated. This kind of control is useful in rack-mounted UPS systems. In contrast, ALS control has a higher modularity, since the controllers of every unit can be equal, without having to change their configuration. In this sense, it is a real democratic control scheme, being suitable for industrial UPS systems able to be expanded. However, transients and stability problems have to be managed by the current-sharing control loops. Finally, the 3C strategy seems to be interesting when forming an ac power ring, since the control communications topology can have the same form.

Depending on the application of the UPS system, the voltage loop of the parallel control structure can be centralized or distributed. When using compact equipment, it can be interesting to have a common central voltage loop, whereas when using modular equipment, it can be appropriate to implement a distributed voltage loop. Table III shows that centralized or MS controllers cannot use a distributed voltage loop, whereas ALS and $3 \mathrm{C}$ strategies can perform both possibilities.

Alternatively, the droop-based control techniques avoid the need for critical communication links. Some improvements have been done to overcome their limitations. However, the tradeoff between power sharing and frequency, voltage, and phase regulation is always present. Noncritical communications can help not only to overcome this inherent tradeoff but also to synchronize the UPS system to an external voltage source, like the utility mains. Furthermore, the virtual output impedance loop lets us use the output impedance of the UPS as an additional control variable. Consequently, the droop method 
can have additional performances like hot-swap operation, harmonic power sharing, and low sensitivity to line impedance unbalances. These performances allow the integration of distributed UPS systems into complex distributed storage and generation systems like electrical microgrids.

\section{REFERENCES}

[1] A. King and W. Knight, Uninterruptible Power Supplies and Standby Power Systems. New York: McGraw-Hill, 2003.

[2] S. Karve, "Three of a kind," Proc. Inst. Electr. Eng.-Review-Power Systems, vol. 46, no. 2, pp. 27-31, Mar. 2000.

[3] S. B. Bekiarov and A. Emadi, "Uninterruptible power supplies: Classification, operation, dynamics, and control," in Proc. IEEE APEC, 2002, pp. 597-604.

[4] M. Prodanović, T. C. Green, and H. Mansir, "A survey of control methods for parallel three-phase inverters connection," in Proc. IEE PEVD Conf. (IEE Conf. Publ. No. 475), Sep. 2000, pp. 472-477.

[5] D. Shanxu, M. Yu, X. Jian, K. Yong, and C. Jian, "Parallel operation control technique of voltage source inverters in UPS," in Proc. IEEE PEDS, 1999, pp. 883-887.

[6] T. Kawabata and S. Higashino, "Parallel operation of voltage source inverters," IEEE Trans. Ind. Appl., vol. 24, no. 2, pp. 281-287, Mar./ Apr. 1988

[7] J. M. Guerrero, L. García de Vicuña, and J. Uceda, "Uninterruptible power supply systems provide protection," IEEE Ind. Electron. Mag., vol. 1, no. 1, pp. 28-38, 2007.

[8] Y. Miyazawa, "Plural inverter synchronizer and control apparatus," U.S. Patent 4733 341, Mar. 22, 1988.

[9] N. Sashida and Y. Yamamoto, "Controlling system for parallel operation of AC output inverters with restrained cross currents," U.S. Patent 5257 180, Oct. 26, 1993.

[10] H. Shirahama, I. Yamato, Y. Sakurai, and N. Tokunaga, "Parallel inverter control apparatus," U.S. Patent 5262 935, Nov. 16, 1993.

[11] K. Kawakami, "Current sharing control in a parallel inverter system," U.S. Patent 5191 519, Mar. 2, 1993.

[12] A. Hirata and Y. Miyazawa, "Parallel connection of different types of AC power supplies of differing capacities," U.S. Patent 5473 528, Dec. 5, 1995.

[13] D. M. Divan and M. Chandorkar, "Method and apparatus for decentralized signal frequency restoration in a distributed UPS system," U.S. Patent 5596 492, Jan. 21, 1997.

[14] F. Tassitino and J. G. Tracy, "Independent load sharing of AC power systems connected in parallel," U.S. Patent 5745 356, Apr. 28, 1998.

[15] J. G. Tracy and F. Tassitino, "Wireless selective tripping of AC power systems connected in parallel," U.S. Patent 5745 355, Apr. 28, 1998.

[16] K. Wallace, G. Mantov, J. Karnes, and J. Roller, "Methods and apparatus for load sharing between parallel inverters in an AC power supply," U.S. Patent 6118 680, Sep. 12, 2000.

[17] C.-C. Wu, H. L. Chou, N.-Y. Chou, N.-Y. Shen, and Y.-J. Chang, "Control method for parallel-connected power converters," U.S. Patent 6906 501, Jun. 15, 2005 .

[18] H.-S. Luo, S.-L. Tian, and C.-M. Tsai, "Parallel redundant power system and method for control of the power system," U.S. Patent no. 6803679 , Oct. 12, 2004

[19] Exide Electronics, Powerware Plus Parallel Redundant System-The Application of Wireless Parallel Technology, pp. 1-29, 1997. Tech. Rep., Rev. B. [Online]. Available: http://www.powerpulse.net/techPaper. php?paperID $=90$ \&page $=1$

[20] H. Hanaoka, M. Nagai, and M. Yanagisawa, "UPS parallel operation analysis considering line resistance influence," Sanyo Denki Co., Tokyo, Japan, Sanyo Denki Tech. Rep. no. 10, Nov. 2000. [Online]. Available: www.sanyodenki.co.jp/techrepo/10e/index.htm

[21] J. Sears, "High-availability power systems: Redundancy options," Power Pulse, Darnell.Com Inc., Angel, CA, 2001. Tech. Rep.

[22] A. P. Martins, A. S. Carvalho, and A. S. Araújo, "Design and implementation of a current controller for the parallel operation of standard UPSs," in Proc. IEEE IECON, 1995, pp. 584-589.

[23] T. Iwade, S. Komiyama, and Y. Tanimura, "A novel small-scale UPS using a parallel redundant operation system," in Proc. IEICE/IEEE INTELEC, 2003, pp. 480-483.

[24] J. Holtz, W. Lotzkat, and K. H. Werner, "A high-power multitransistorinverter uninterruptible power supply system," IEEE Trans. Power Electron., vol. 3, no. 3, pp. 278-285, Jul. 1988.
[25] J. Holtz and K. H. Werner, "Multi-inverter UPS system with redundant load sharing control," IEEE Trans. Ind. Electron., vol. 37, no. 6, pp. 506513, Dec. 1990.

[26] H. van der Broeck and U. Boeke, "A simple method for parallel operation of inverters," in Proc. IEEE INTELEC Conf., 1998, pp. 143-150.

[27] C. S. Lee, S. Kim, C. B. Kim, S. C. Hong, J. S. Yoo, S. W. Kim, C. H. Kim, S. H. Who, and S. Y. Sun, "Parallel U.P.S. with a instantaneous current sharing control," in Proc. IEEE IECON Conf., 1998, pp. 568-573.

[28] Y. Pei, G. Jiang, X. Yang, and Z. Wang, "Auto-master-slave control technique of parallel inverters in distributed AC power systems and UPS," in Proc. IEEE PESC, 2004, pp. 2050-2053.

[29] W.-C. Lee, T.-K. Lee, S.-H. Lee, K.-H. Kim, D.-S. Hyun, and I.-Y. Suh, "A master and slave control strategy for parallel operation of three phase UPS systems with different ratings," in Proc. IEEE APEC, 2004, pp. 456-462.

[30] J. F. Chen and C.-L. Chu, "Combination voltage-controlled and currentcontrolled PWM inverters for UPS parallel operation," IEEE Trans. Power Electron., vol. 10, no. 5, pp. 547-558, Sep. 1995.

[31] S. Tamai and M. Kinoshita, "Parallel operation of digital controlled UPS system," in Proc. IEEE IECON, 1991, pp. 326-331.

[32] Y. J. Cheng and E. K. K. Sng, "A novel communication strategy for decentralized control of paralleled multi-inverter systems," IEEE Trans. Power Electron., vol. 21, no. 1, pp. 148-156, Jan. 2006

[33] X. Sun, Y.-S. Lee, and D. Xu, "Modeling, analysis, and implementation of parallel multi-inverter system with instantaneous average-current-sharing scheme," IEEE Trans. Power Electron., vol. 18, no. 3, pp. 844-856, May 2003.

[34] Y. Xing, L. Huang, S. Sun, and Y. Yan, "Novel control for redundant parallel UPSs with instantaneous current sharing," in Proc. IEEE PCC Conf., Osaka, Japan, 2002, pp. 959-963.

[35] Y.-K. Chen, T.-F. Wu, Y.-E. Wu, and C.-P. Ku, "A current-sharing control strategy for paralleled multi-inverter systems using microprocessor-based robust control," in Proc. IEEE TENCON, 2001, pp. 647-653.

[36] Y.-K. Chen, Y.-E. Wu, and C.-P. Ku, "ACSS for paralleled multi-inverter systems with DSP-based robust controls," IEEE Trans. Aerosp. Electron. Syst., vol. 39, no. 3, pp. 1002-1015, Jul. 2003.

[37] S. Sun, L.-K. Wong, Y.-S. Lee, and D. Xu, "Design and analysis of an optimal controller for parallel multi-inverter systems," IEEE Trans. Circuits Syst. II, Exp. Briefs, vol. 52, no. 1, pp. 56-61, Jan. 2006.

[38] Z. He, Y. Xing, and Y. Hu, "Low cost compound current sharing control for inverters in parallel operation," in Proc. IEEE PESC, 2004, pp. 222-227.

[39] H.-M. Hsieh, T.-F. Wu, H.-S. Nien, Y.-E. Wu, and Y.-K. Chen, "A compensation strategy for parallel inverters to achieve precise weighting current distribution," in Conf. Rec. IEEE IAS Annu. Meeting, 2005, pp. 954-960.

[40] H. Oshima, Y. Miyakawa, and A. Hirata, "Parallel redundant UPS with instantaneous PWM control," in Proc. IEEE INTELEC, 1991, pp. 436-442.

[41] J. Tao, H. Lin, J. Zhang, and J. Ying, "A novel load sharing control technique for paralleled inverters," in Proc. IEEE PESC Conf., 2003, pp. $1432-1437$.

[42] T. F. Wu, Y.-K. Chen, and Y.-H. Huang, "3C strategy for inverters in parallel operation achieving an equal current distribution," IEEE Trans. Ind. Electron., vol. 47, no. 2, pp. 273-281, Apr. 2000.

[43] S. J. Chiang, C. H. Lin, and C. Y. Yen, "Current limitation control technique for parallel operation of UPS inverters," in Proc. IEEE PESC, 2004, pp. $1922-1926$.

[44] L. Mihalache, "Parallel control technique with no intercommunication signals for resonant controller-based inverters," in Conf. Rec. IEEE IAS Аnnu. Meeting, 2003, pp. 1882-1889.

[45] M. C. Chandorkar, D. M. Divan, Y. Hu, and B. Barnajee, "Novel architectures and control for distributed UPS systems," in Proc. IEEE APEC, 1994, pp. 683-689.

[46] M. C. Chandorkar, D. M. Divan, and R. Adapa, "Control of parallel connected inverters in standalone AC supply systems," IEEE Trans. Ind. Appl., vol. 29, no. 1, pp. 136-143, Jan./Feb. 1993.

[47] M. C. Chandorkar and D. M. Divan, "Decentralized operation of distributed UPS systems," in Proc. IEEE PEDES, 1996, pp. 565-571.

[48] A. Tuladhar, H. Jin, T. Unger, and K. Mauch, "Parallel operation of single phase inverter modules with no control interconnections," in Proc. IEEE APEC, 1997, pp. 94-100.

[49] F. Zanxuan and Q. Wenlong, "A current share method for parallel singlephase DC/AC inverter without control interconnection," in Proc. IEEE IPEMC, 2004, pp. 953-955.

[50] X. Chen, Y. Kang, and J. Chen, "Operation, control technique of parallel connected high power three-phase inverter," in Proc. IEEE IPEMC, 2004, pp. 956-959. 
[51] M. Xie, Y. Li, K. Cai, P. Wang, and X. Sheng, "A novel controller for parallel operation of inverters based on decomposing of output currents," in Conf. Rec. IEEE IAS Annu. Meeting, 2005, pp. 1671-1676.

[52] Y. B. Byun, T. G. Koo, K. Y. Joe, E. S. Kim, J. I. Seo, and D. H. Kim, "Parallel operation of three-phase UPS inverters by wireless load sharing," in Proc. IEEE INTELEC, 2000, pp. 526-532.

[53] A. Daneshpooy, "Dead-beat control of parallel connected UPS," in Proc. IEEE APEC, 2002, pp. 580-583.

[54] C. Mak and L. Bolster, "Bus-tie and load share technique in a ring bus system with multiple power inverters," in Proc. IEEE APEC, 2005, pp. 871-874.

[55] U. Borup, F. Blaabjerg, and P. N. Enjeti, "Sharing of nonlinear load in parallel-connected three-phase converters," IEEE Trans. Ind. Appl., vol. 37, no. 6, pp. 1817-1823, Nov./Dec. 2001.

[56] S. J. Chiang and J. M. Chang, "Parallel operation of series-connected PWM voltage regulators without control interconnection," Proc. Inst. Electr. Eng.-Electr. Power Appl., vol. 148, no. 2, pp. 141-147, Mar. 2001

[57] L. Chen, X. Xiao, C. Gong, and Y. Yan, "Circulating current's characteristics analysis and the control strategy of parallel system based on double close-loop controlled VSI," in Proc. IEEE PESC, 2004, pp. 4791-4797.

[58] E. A. A. Coelho, P. Cabaleiro, and P. F. Donoso, "Small-signal stability for parallel-connected inverters in stand-alone AC supply systems," IEEE Trans. Ind. Appl., vol. 38, no. 2, pp. 533-542, Mar./Apr. 2002.

[59] E. A. A. Coelho, P. Cabaleiro, and P. F. Donoso, "Small signal stability for single phase inverter connected to stiff AC system," in Conf. Rec. IEEE IAS Annu. Meeting, 1999, pp. 2180-2187.

[60] J. M. Guerrero, L. García de Vicuña, J. Miret, J. Matas, and J. Cruz, "Output impedance performance for parallel operation of UPS inverters using wireless and average current-sharing controllers," in Proc. IEEE PESC Conf., 2004, pp. 2482-2488.

[61] L. Xinchun, F. Feng, D. Shanxu, K. Yong, and C. Jian, "Modeling and stability analysis for two paralleled UPS with no control interconnection," in Proc. IEEE IEMDC Conf., 2003, pp. 1772-1776.

[62] L. Xinchun, F. Feng, D. Shanxu, K. Yong, and C. Jian, "The droop characteristic decoupling control of parallel connected UPS with no control interconnection," in Proc. IEEE IEMDC Conf., 2003, pp. 1777-1780.

[63] E. K. Sato, A. Kawamura, and R. Fujii, "Theoretical and experimental verification of independent control for parallel-connected multi-UPS's," in Proc. IEEE INTELEC, 2003, pp. 485-492.

[64] Y. Sun, W. Qu, and B. Liang, "An advanced synchronization and currentsharing method for paralleled DC/AC inverters without interconnection," in Proc. IEEE ICEMS, 2005, pp. 1013-1016.

[65] J. M. Guerrero, L. García de Vicuña, J. Matas, M. Castilla, and J. Miret, "A wireless controller to enhance dynamic performance of parallel inverters in distributed generation systems," IEEE Trans. Power Electron., vol. 9, no. 5, pp. 1205-1213, Sep. 2004.

[66] J. M. Guerrero, L. García de Vicuña, J. Matas, M. Castilla, and J. Miret, "Output impedance design of parallel-connected UPS inverters with wireless load-sharing control," IEEE Trans. Ind. Electron., vol. 52, no. 4, pp. 1126-1135, Aug. 2005.

[67] J. M. Guerrero, J. Matas, L. García de Vicuña, M. Castilla, and J. Miret, "Wireless-control strategy for parallel operation of distributed-generation inverters," IEEE Trans. Ind. Electron., vol. 53, no. 5, pp. 1461-1470, Oct. 2006.

[68] Y. Ito and O. Iyama, "Parallel redundant operation of UPS with robust current minor loop," in Proc. IEEE PCC, 1997, pp. 489-495.

[69] K. Wallace and G. Mantov, "Wireless load sharing of single phase telecom inverters," in Proc. IEEE INTELEC, 1999, pp. 1-7.

[70] H.-P. Glauser, M. Keller, A. Plüs, M. Schwab, and R. Scherwey, "New inverter module with digital control for parallel operation," in Proc. IEEE TELESCON, 2000, pp. 265-269.

[71] S. J. Chiang, C. Y. Yen, and K. T. Chang, "A multimodule parallelable series-connected PWM voltage regulator," IEEE Trans. Ind. Electron., vol. 48 , no. 3, pp. 506-516, Jun. 2001.

[72] T. Skjellness, A. Skjellness, and L. E. Norum, "Load sharing for parallel inverters without communication," in Proc. NORPIE, 2002, pp. 1-4.

[73] H. Hanaoka, M. Nagai, and M. Yanagisawa, "Development of a novel parallel redundant UPS," in Proc. IEEE INTELEC, 2003, pp. 493-498.

[74] J. M. Guerrero, J. Matas, L. García de Vicuña, M. Castilla, and J. Miret, "Decentralized control for parallel operation of distributed generation inverters using resistive output impedance," IEEE Trans. Ind. Electron., vol. 54, no. 2, pp. 994-1004, Apr. 2007.

[75] S. K. Mazumder, M. Tahir, and K. Acharya, "Master-slave currentsharing control of a parallel DC-DC converter system over an RF communication interface," IEEE Trans. Ind. Electron., vol. 55, no. 1, pp. 59-66, Jan. 2008 .
[76] H. H. Kim, N. K. Min, S. W. Kim, J. S. Koo, S. H. Woo, and Y. S. Sun, "Modular parallel U.P.S. for communication power system," in Proc. IEEE INTELEC, 1999, pp. 1-6.

[77] A. Tuladhar, H. Jin, T. Unger, and K. Mauch, "Control of parallel inverters in distributed AC power systems with consideration of line impedance," IEEE Trans. Ind. Appl., vol. 36, no. 1, pp. 131-138, Jan./Feb. 2000.

[78] M. N. Marwali, J.-W. Jung, and A. Keyhani, "Control of distributed generation systems-Part II: Load sharing control," IEEE Trans. Power Electron., vol. 19, no. 6, pp. 1551-1561, Nov. 2004

[79] H. Deng, R. Oruganti, and D. Srinivasan, "Neural controller for UPS inverters based on B-Spline network," IEEE Trans. Ind. Electron., vol. 55, no. 2, pp. 899-909, Feb. 2008.

[80] A. Nasiri, Z. Nie, S. B. Bekiarov, and A. Emadi, "An on-line UPS system with power factor correction and electric isolation using BIFRED converter," IEEE Trans. Ind. Electron., vol. 55, no. 2, pp. 722-730, Feb. 2008.

[81] H. Deng, R. Oruganti, and D. Srinivasan, "A simple control method for high-performance UPS inverters through output-impedance reduction," IEEE Trans. Ind. Electron., vol. 55, no. 2, pp. 888-898, Feb. 2008.

[82] G. Escobar, A. A. Valdez, J. Leyva-Ramos, and P. Mattavelli, "Repetitivebased controller for a UPS inverter to compensate unbalance and harmonic distortion," IEEE Trans. Ind. Electron., vol. 54, no. 1, pp. 504-510, Feb. 2007.

[83] G. Willmann, D. F. Coutinho, L. F. A. Pereira, and F. B. Libano, "Multiple-loop H-infinity control design for uninterruptible power supplies," IEEE Trans. Ind. Electron., vol. 54, no. 3, pp. 1591-1602, Jun. 2007

[84] G. Escobar, P. Mattavelli, A. M. Stankovic, A. A. Valdez, and J. Leyva-Ramos, "An adaptive control for UPS to compensate unbalance and harmonic distortion using a combined capacitor/load current sensing," IEEE Trans. Ind. Electron., vol. 54, no. 2, pp. 839-847, Apr. 2007.

[85] H. Deng, R. Oruganti, and D. Srinivasan, "Analysis and design of iterative learning control strategies for UPS inverters," IEEE Trans. Ind. Electron., vol. 54, no. 3, pp. 1739-1751, Jun. 2007.

[86] F. Botteron and H. Pinheiro, "A three-phase UPS that complies with the standard IEC 62040-3," IEEE Trans. Ind. Electron., vol. 54, no. 4, pp. 2120-2136, Aug. 2007.

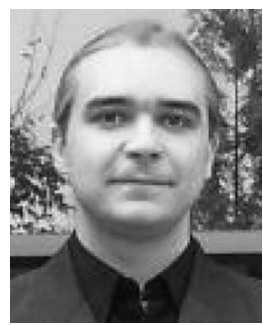

Josep M. Guerrero (S'01-M'04-SM'08) received the B.S. degree in telecommunications engineering, the M.S. degree in electronics engineering, and the $\mathrm{Ph} . D$. degree in power electronics from the Technical University of Catalonia, Barcelona, Spain, in 1997, 2000 , and 2003, respectively.

From 1998 to 2004, he was an Assistant Professor with the Department of Automatic Control Systems and Computer Engineering, Technical University of Catalonia. In 2004, he became a Senior Lecturer, where he teaches courses on digital signal processing, control theory, microprocessors, and renewable energy. Since 2004, he has been responsible for the Sustainable Distributed Generation and Renewable Energy Research Group, Escola Industrial de Barcelona, Barcelona. His research interests include photovoltaics, wind energy conversion, uninterruptible power supplies, storage energy systems, and microgrids.

Dr. Guerrero is an Associate Editor of the IEEE TRANSACTIONS ON Industrial Electronics and the IEEE TRANSACTIONS ON POWER ELECTRONICS. He is involved with several IEEE Industrial Electronics Society (IES) committees, and he usually chairs and organizes sessions in IES and Power Electronics Society conferences.

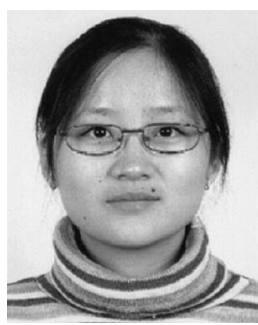

Lijun Hang was born in Jiaxing, China, in 1979. She received the B.S. and Ph.D. degrees from Zhejiang University, Hangzhou, China, in 2002 and 2008, respectively, both in electrical engineering.

She is currently with the College of Electrical Engineering, Zhejiang University. She is the holder of a patent and has been cooperated in several industrial projects with SANTAK Corporation, Shenzhen, China. She was responsible for the standardization research of communication in power electronic systems. She has published more than 40 papers in journals and conferences. Her research interests include digital control in power electronics, power factor correction, distributed power systems, and communication interface standards in power electronics system integration.

Dr. Hang is a Referee for various IEEE Transactions. 


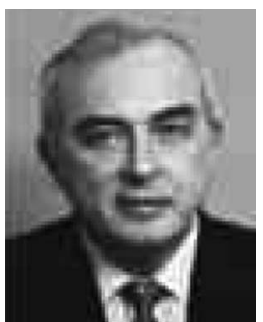

Javier Uceda (M'83-SM'91-F'05) received the M.Sc. and Ph.D. degrees from the Universidad Politécnica de Madrid (UPM), Madrid, Spain, in 1976 and 1979, respectively, both in electrical engineering.

Since 1986, he has been a Professor of electronics with UPM. He has published several books and more than 300 papers in journals and conference proceedings. He has been a member of the Editorial Board of the European Power Electronics and Drives Journal. His research interests are in power electronics, particularly high frequency high-density power converters.

Dr. Uceda is currently a Senior AdCom member of the IEEE Industrial Electronics Society. He was a member of the Steering Committee, European Power Electronics and Drives Association. He was the Technical Program Committee Chairman of the IEEE Power Electronics Specialists Conference in 1992 and the General Chairman of the European Conference on Power Electronics and Applications in 1995. 